Original Article

\title{
The Effect of Synbiotic Shake on Blood Glucose and Lipid Profile in Hyperglycemia Wistar Rats
}

\author{
Lily Arsanti Lestari ${ }^{1,2^{*}}$, Inas Nur Hafizhah ${ }^{3}$, Happy Nurlita Octavinanda ${ }^{3}$, Latifah Mahdiyati ${ }^{3}$, Refdiana \\ Dewi $^{3}$, Perdana Samekto Tyasnugroho Suyoto ${ }^{1}$, Emy Huriyati ${ }^{1}$, Sunarti $^{4}$ \\ ${ }^{1}$ Department of Nutrition \& Health, Faculty of Medicine, Public Health, and Nursing, Universitas Gadjah Mada, \\ Jl. Farmako, Sekip Utara, Yogyakarta, Indonesia 55281; lily_al@ugm.ac.id \\ ${ }^{2}$ Institute for Halal Industry and System, Universitas Gadjah Mada, Yogyakarta, Indonesia 55281 \\ ${ }^{3}$ Undergraduate Program of Nutrition \& Health, Faculty of Medicine, Public Health, and Nursing, Universitas \\ Gadjah Mada, Jl. Farmako, Sekip Utara, Yogyakarta, Indonesia 55281 \\ ${ }^{4}$ Department of Biochemistry, Faculty of Medicine, Public Health, and Nursing, Universitas Gadjah Mada, Jl. \\ Farmako, Sekip Utara, Yogyakarta, Indonesia 55281 \\ *Corresponding author: Lily Arsanti Lestari I Email: lily_al@ugm.ac.id
}

Received: 11 October 2020; Revised: 02 November 2020; Accepted: 18 December 2020; Published: 31 December 2020

\begin{abstract}
Several studies found that the probiotic bacterias such as Lactobacillus acidophilus La5 and Bifidobacterium lactis $\mathrm{Bb} 12$ could prevent glycemia and control the blood lipid profiles. Currently, a probiotic product such as yogurt is not preferable by some consumers since the taste is sour. Therefore, this study was conducted to develop milkshakes supplemented by probiotics Lactobacillus acidophilus La5 and Bifidobacterium lactis $\mathrm{Bb} 12$ which are expected to be more acceptable and have a beneficial effect with the addition of prebiotics and soluble fiber glucomannan. This study aims to determine the effect of synbiotic shakes on fasting blood glucose levels and lipid profiles in hyperglycemia Wistar rat models. The study design was a pre-posttest controlled group with 48 male Wistar rats divided into 8 groups, namely the healthy control group (I); hyperglycemia control group (II); group III that received metformin; group IV that received synbiotic shake with La5 + FOS; group V that received synbiotic shake La5 + inulin; group VI that received synbiotic shake Bb12 + FOS; group VII that received synbiotic shake Bb12 + inulin; and group VIII that received synbiotic shake La5 + $\mathrm{Bb} 12$ + FOS. The dose of the intervention was $3.6 \mathrm{ml} /$ day with an intervention duration of 28 days. The results showed that the differences in blood glucose levels were not significant ( $p>0.05)$ except for groups IV and VI that experienced a significant increase $(\mathrm{p}<0.05)$. The differences in lipid profiles showed insignificant changes in LDL levels except in groups IV and V, a significant increase in HDL levels ( $p<0.05$ ) in group V and VI, and insignificant change in triglycerides except in group VI. It can be concluded that the administration of synbiotic shakes with a variety of prebiotics Lactobacillus acidophilus La5 and Bifidobacterium lactis Bb12 for 4 weeks were able to maintain fasting blood glucose levels and lipid profiles in hyperglycemic rats.
\end{abstract}

Keywords: hyperglycemia; synbiotic shake; Lactobacillus acidophilus La5; Bifidobacterium lactis Bb12; fasting blood glucose; lipid profile 


\section{INTRODUCTION}

Hyperglycemia is a condition where high blood glucose levels exceeding the normal range continuously and are commonly associated with diabetes mellitus [1]. Diabetes mellitus is a metabolic disease characterized by high blood glucose levels due to impaired insulin secretion, impaired insulin utilization, or both [2]. Diabetes mellitus type 2 is exclaimed the silent killer because it could increase the risk of various complications. The various complications that would happen such as retinopathy, heart disease, kidney problems, infections, blood vessel disorders, strokes, and many more. As a result of complications from the disease, people with diabetes mellitus will experience a decrease in quality of life and even increase the risk of mortality [3,4]. Cardiovascular disease is the principal cause of death in people with diabetes mellitus type 2 because the risk of developing cardiovascular disease in people with diabetes mellitus type 2 is two to four times higher than that of cardiovascular disease in non-diabetic people.

In people with diabetes mellitus type 2, diet or dietary arrangements are necessary. According to PERKENI [5], the diet for people with diabetes mellitus type 2 must engage the 3J principles, namely the right amount (Jumlah), type (Jenis), and schedule (Jadwal). The compliance of 3J principles, especially types of food, could make food choices for people with diabetes mellitus type 2 more restricted than normal people. One of the food ingredients that can be given to people with diabetes mellitus type 2 is functional food products. Functional food is natural food or processed food that contains active biological components, known or unknown, which is a certain amount that does not cause toxic effects, has been clinically proven and has been documented to provide health benefits for the prevention, management, and treatment of chronic disease [6].

The components of functional food include probiotics, prebiotics, and dietary fiber. Probiotic bacteria were effective in preventing cardiovascular complications in people with diabetes mellitus type 2 is Lactobacillus reuteri, while the effectiveness of other bacteria in preventing complications, for example, the combination of Lactobacillus acidophilus and Bifidobacterium lactis, is still in doubt, thus, that further research is needed to discover on the effectiveness of the two bacteria $[7,8]$. The combination of probiotic bacteria, Lactobacillus acidophilus, and Bifidobacterium lactis, had been found in many commercial yogurt products in Indonesia. However, the level of yogurt products containing probiotics consumption is still low because of its sour taste that is less acceptable to consumers. Therefore, we developed synbiotic shakes, which is a type of milk-based drink containing Lactobacillus acidophilus or Bifidobacterium lactis as well as prebiotics fructooligosaccharide and inulin and soluble fiber glucomannan, that expected to affect on fasting blood glucose (FBG) levels and lipid profiles.

\section{MATERIALS AND METHODS}

\subsection{Study design, Period and Location}

The study design was a quasi-experimental study on Wistar rats with a pre-posttest controlled group design. The research was conducted from Juni until October 2019. The maintenance and treatment of experimental animals were carried out in the Integrated Research and Testing Laboratory (LPPT) Unit 4 of Universitas Gadjah Mada (UGM) and blood glucose levels and lipid profiles analysis were carried out in LPPT Unit 2 UGM, Yogyakarta, Indonesia. 


\subsection{Materials and Equipments}

The ingredients that used in this study include ingredients for synbiotic shakes, namely powdered skim milk, whey powder, maltodextrin, glucomannan, FOS, inulin, sucralose, tricalcium phosphate, Lactobacillus acidophilus La5, Bifidobacterium lactis $\mathrm{Bb} 12, \mathrm{NaCl}$, cocoa powder, and sucrose. The feed was formulated according to AIN-93M [9] which contained corn starch, casein, sucrose, soybean oil, fiber, mineral mix, vitamin mix, L-cystine, and choline bitartrate (Table 1). The ingredients used for animal treatment were nicotinamide, streptozotocin, synbiotic shake, ketamine, and distilled water. The tools used in this study are digital scales, hand mixers, blenders or shakers, thermometers, measuring cups, milk bottles, cutlery, a stainless steel cage for 5 rats, feed container, drinking container, forced feeding needles, injection syringe, latex gloves, eppendorf tube, and microhematocrit.

Table 1. AIN-93M Standard Feed Composition

\begin{tabular}{|c|c|}
\hline Ingredients & Composition (gram/kg diet) \\
\hline Corn starch & 620.70 \\
\hline Casein & 140 \\
\hline Sucrose & 100 \\
\hline Soybean oil & 40 \\
\hline Fiber & 50 \\
\hline Mineral mix & 35 \\
\hline Vitamin mix & 10 \\
\hline L-cystine & 1.8 \\
\hline Choline bitartrate & 2.5 \\
\hline Total & 1000 \\
\hline Energy (Kcal) & 3619 \\
\hline
\end{tabular}

\subsection{Experimental Animal and Intervention}

The experimental animals used in this study were male Wistar rats preserved in LPPT Unit 4 UGM. As many as 48 Wistar rats were divided into eight treatment groups. The inclusion criteria of experimental animals were male Wistar rats, 10-12 weeks of age, 180-260 grams in weight, and rats in healthy condition, while rats that died during the study would be dropped out. This research has received approval from the Ethics Commission of the Faculty of Medicine, Public Health and Nursing Universitas Gadjah Mada with the protocol number: KE/0657/05/2019.

Before undergoing the study, all rats underwent adaptations to adapt to their surroundings. The diabetes induction agent that being used was streptozotocin (STZ) dissolved in acid buffer solution and nicotinamide (NA) dissolved in phosphate buffer saline solution. Hyperglycemia induction was performed by giving an intraperitoneal injection of $230 \mathrm{mg} / \mathrm{kg}$ NA to fasted rats for one night. Then as much as $65 \mathrm{mg} / \mathrm{kg}$ of STZ was injected into rats 15 minutes after NA injection [10]. Determination of the condition of hyperglycemia in rats was carried out by analyzing the fasting blood glucose levels of the rats. Rats were declared hyperglycemia when their fasting blood glucose levels had reached levels $>110 \mathrm{mg} / \mathrm{dL}$ [11].

All experimental animals in this study were given AIN-93M standard diet and drink ad libitum. For the control group, the forced feeding was administered in the form of distilled water 
while the treatment group received forced feeding in a variety of synbiotic shakes form. The dose of synbiotic shake in this study was $3.6 \mathrm{ml} /$ day.

Experimental rats were divided into 8 groups of 6 rats, namely

1. Group I : the normal control group, healthy rats that received distilled water;

2. Group II : the hyperglycemia rats that received distilled water;

3. Group III : the hyperglycemia rats that received metformin;

4. Group IV : the hyperglycemic rats that received synbiotic shake containing Lactobacillus acidophilus La5 and FOS;

5. Group V : the hyperglycemic rats that received synbiotic shake containing Lactobacillus acidophilus La5 and inulin;

6. Group VI : the hyperglycemic rats that received synbiotic shake containing Bifidobacterium lactis Bb12 and FOS;

7. Group VII : the hyperglycemic rats that received synbiotic shake containing Bifidobacterium lactis Bb12 and inulin;

8. Group VIII : the hyperglycemic rats that received synbiotic shake containing Lactobacillus acidophilus La5, Bifidobacterium lactis Bb12 and FOS.

The blood sample was taken as much as $1.5 \mathrm{ml}$. Blood samples were taken from rats that had been fasted for \pm 12 hours. Blood was drawn through the eye (retro-orbital plexus) by sedating the rats first with ketamine.

\subsection{Analysis of Fasting Glucose Levels and Lipid Profile}

Blood glucose levels were analyzed using the enzymatic spectrophotometric GOD-PAP method with the principle that glucose in the sample is oxidized to form gluconic acid and hydrogen peroxide. Hydrogen peroxide 4-Aminoantipyrine with phenol indicator catalyzed with the POD to form quinoneimine and water. The sample then was measured for absorbance using a spectrophotometer with a wavelength of $540 \mathrm{~nm}$. Blood glucose levels are expressed in $\mathrm{mg} / \mathrm{dL}$ units.

Measurement of HDL and LDL levels using the Cholesterol Oxidase-Peroxidase Aminoatypirine Phenol (CHOD-PAP) method and HDL precipitation. Triglycerides levels was measured using the Glycerol 3 Phospate Oxidase-Phenol Amino Phenazone (GPO-PAP) method. Lipid profile testing is performed using colorimetric enzymatic principles, namely by using enzymes to produce a certain color and then the color absorption is measured using a spectrophotometer. HDL, LDL, and TG levels are expressed in $\mathrm{mg} / \mathrm{dL}$ units.

\subsection{Statistical Analysis}

Research data were analyzed using the SPSS 20 program with a power of $90 \%$ and a level of significance was 0.05 . The data normality test was performed using the test Shapiro-Wilk. Pre and post-intervention data in each group analyzed by using the paired T-test. Meanwhile, if the data was not normally distributed, the Wilcoxon test method would be used. The differences test of all groups was analyzed by using One-way ANOVA followed by the Post Hoc Bonferroni test when the data is normally distributed. If the data was not normally distributed, then the non-parametric Kruskal Wallis test was performed and the test continued with Mann-Whitney. Observation of blood drawn was conducted twice, i.e. before the intervention and after the intervention for 28 days. 


\section{RESULTS AND DISCUSSION}

\subsection{Feed Intake and Body Weight Gain}

The results showed that there was no significant difference in the mean value of AIN93M feed intake between groups ( $p>0.05$ ), this indicates that the feed might not give different effect with the outcome between groups. While in the other groups there were significant differences in feed intake for each treatment period ( $\mathrm{p}<0.05$ ), namely in groups III and V (Table 2).

Table 2. Feed consumption during the study

\begin{tabular}{|c|c|c|c|c|c|c|}
\hline \multirow{2}{*}{$\begin{array}{l}\text { Intervention } \\
\text { group }\end{array}$} & \multicolumn{5}{|c|}{ AIN93M Standard Feed Intake (grams) } & \multirow[t]{2}{*}{$p$} \\
\hline & $\begin{array}{l}\text { Induction } \\
\text { incubation }\end{array}$ & $\begin{array}{l}\text { Intervention of } \\
\text { first week }\end{array}$ & $\begin{array}{l}\text { Intervention of } \\
\text { second week }\end{array}$ & $\begin{array}{c}\text { Intervention of } \\
\text { third week }\end{array}$ & $\begin{array}{c}\text { Intervention of } \\
\text { fourth week }\end{array}$ & \\
\hline$I(n=6)$ & $19.13 \pm 0.78$ & $18.83 \pm 0.83$ & $17.79 \pm 1.48$ & $17.86 \pm 1.83$ & $17.20 \pm 1.75$ & 0.143 \\
\hline II $(n=6)$ & $18.16 \pm 1.29$ & $18.84 \pm 1.02$ & $18.59 \pm 1.21$ & $18.85 \pm 0.97$ & $18.09 \pm 1.26$ & 0.680 \\
\hline III $(n=6)$ & $18.05 \pm 0.85^{\mathrm{ab}}$ & $18.84 \pm 0.87 \mathrm{a}$ & $18.56 \pm 0.62^{\mathrm{ab}}$ & $18.59 \pm 0.75^{\mathrm{ab}}$ & $17.20 \pm 1.26^{\mathbf{b}}$ & 0.032 \\
\hline IV $(n=6)$ & $18.46 \pm 0.90$ & $18.54 \pm 0.75$ & $17.50 \pm 1.31$ & $17.95 \pm 0.65$ & $16.98 \pm 1.14$ & 0.055 \\
\hline$V(n=6)$ & $17.66 \pm 1.29^{\mathrm{ab}}$ & $18.83 \pm 0.53^{\mathrm{a}}$ & $18.05 \pm 0.91^{\mathrm{ab}}$ & $17.58 \pm 1.17^{\mathrm{ab}}$ & $16.61 \pm 1.42^{b}$ & 0.032 \\
\hline VI $(n=6)$ & $17.67 \pm 1.42$ & $18.05 \pm 1.33$ & $17.52 \pm 1.50$ & $17.52 \pm 1.57$ & $16.49 \pm 1.20$ & 0.421 \\
\hline VII $(n=6)$ & $17.55 \pm 0.65$ & $18.68 \pm 0.65$ & $16.83 \pm 1.70$ & $18.32 \pm 1.05$ & $17.40 \pm 1.43$ & 0.078 \\
\hline VIII $(n=6)$ & $17.90 \pm 0.66$ & $18.57 \pm 1.01$ & $17.36 \pm 1.35$ & $18.37 \pm 0.80$ & $17.42 \pm 1.42$ & 0.236 \\
\hline$p$ & 0.176 & 0.807 & 0.278 & 0.444 & 0.587 & \\
\hline
\end{tabular}

Remarks:

p: One-Way ANOVA test

a b: Post Hoc Bonferroni test

the same letter that is in the same row indicated insignificant

Table 3 showed that the body weight of rats' tend to increase every week in all treatment groups during the study significantly $(\mathrm{p}<0.05)$, except in group VII which had an insignificant increase in body weight $(\mathrm{p}>0.05)$.

Table 3. Rats Body Weight Gain during the Study

\begin{tabular}{|c|c|c|c|c|c|c|c|}
\hline \multirow[t]{2}{*}{ Groups } & \multicolumn{6}{|c|}{ Body weight gain (grams) } & \multirow[t]{2}{*}{$p$} \\
\hline & $\begin{array}{c}\text { First } \\
\text { adaptation }\end{array}$ & $\begin{array}{l}\text { Induction } \\
\text { adaptation }\end{array}$ & $\begin{array}{l}\text { Intervention of } \\
1^{\text {st }} \text { week }\end{array}$ & $\begin{array}{l}\text { Intervention of } \\
2^{\text {nd }} \text { week }\end{array}$ & $\begin{array}{l}\text { Intervention of } \\
3^{\text {rd }} \text { week }\end{array}$ & $\begin{array}{l}\text { Intervention of } \\
4^{\text {th }} \text { week }\end{array}$ & \\
\hline $\mathrm{I}(\mathrm{n}=6)$ & $245.17 \pm 29.86$ & $245.83 \pm 49.29$ & $288.33 \pm 29.62$ & $273.00 \pm 38.60$ & $294.17 \pm 32.43$ & $304.67 \pm 38.13$ & $0.035^{p}$ \\
\hline II $(\mathrm{n}=6)$ & $187.33 \pm 38.39$ & $207.67 \pm 33.64$ & $232.67 \pm 33.25$ & $255.83 \pm 32.55$ & $276.17 \pm 30.16$ & $301.00 \pm 29.50$ & $<0.001^{p}$ \\
\hline III $(n=6)$ & $223.67 \pm 39.13$ & $230.83 \pm 30.80$ & $242.83 \pm 35.62$ & $255.83 \pm 32.55$ & $275.33 \pm 30.19$ & $292.33 \pm 33.39$ & $0.010^{\mathrm{p}}$ \\
\hline IV $(n=6)$ & $226.33 \pm 37.60$ & $247.33 \pm 25.35$ & $266.17 \pm 29.28$ & $281.83 \pm 31.27$ & $298.00 \pm 28.66$ & $310.83 \pm 24.42$ & $<0.001^{\mathrm{p}}$ \\
\hline$V(n=6)$ & $238.33 \pm 28.59$ & $242.33 \pm 28.08$ & $263.67 \pm 28.03$ & $279.67 \pm 26.30$ & $296.33 \pm 29.64$ & $315.00 \pm 31.07$ & $<0.001^{\mathrm{p}}$ \\
\hline VI $(n=6)$ & $242.83 \pm 21.64$ & $244.00 \pm 21.58$ & $264.83 \pm 22.94$ & $285.67 \pm 25.05$ & $304.17 \pm 25.66$ & $322.17 \pm 26.24$ & $<0.001^{p}$ \\
\hline VII (n=6) & $254.67 \pm 29.66$ & $245.00 \pm 24.83$ & $255.67 \pm 24.41$ & $266.50 \pm 28.65$ & $280.83 \pm 33.15$ & $292.83 \pm 39.84$ & $0.096 \mathrm{p}$ \\
\hline VIII $(n=6)$ & $259.00 \pm 38.14$ & $246.33 \pm 27.34$ & $262.33 \pm 22.67$ & $278.00 \pm 17.69$ & $293.00 \pm 13.41$ & $322.50 \pm 38.13$ & $0.001 \mathrm{p}$ \\
\hline$p$ & $0.019 \mathrm{p}$ & $0.360 \mathrm{p}$ & $0.074 \mathrm{p}$ & $0.510 \mathrm{p}$ & $0.542 p$ & $0.602^{p}$ & \\
\hline
\end{tabular}




\subsection{Effect of Synbiotic Shake Administration on Blood Glucose Levels}

The blood glucose levels of STZ-NA-induced rats increased above $120 \mathrm{mg} / \mathrm{dL}$ in all groups. This condition includes hyperglycemia that is characterized by fasting blood glucose levels $>110$ $\mathrm{mg} / \mathrm{dl}$ in experimental animals [11]. The means of blood glucose levels data were presented in Table 4. The results of the paired sample T-test showed a decrease in glucose fasting blood level although it was not significant ( $p>0.05$ ) in group III and group V. An insignificant increased in blood glucose levels ( $p>0.05$ ) occurred in I, II, VII, and VIII groups. Meanwhile, in IV and VI groups, there was a significant increase in fasting blood glucose levels $(\mathrm{p}<0.05)$. The differences in fasting blood glucose levels before and after intervention in all groups were not statistically different $(p>0.05)$.

Table 4. Fasting Blood Glucose Level during the Study

\begin{tabular}{|c|c|c|c|}
\hline \multirow{2}{*}{ Group } & \multicolumn{3}{|c|}{ Fasting Blood Glucose Level (mg/dL) } \\
\hline & Pre & Post & Delta \\
\hline I & $122.08 \pm 11.57$ & $129.07 \pm 17.01$ & $6.98 \pm 22.38$ \\
\hline II & $122.08 \pm 21.60$ & $134.38 \pm 2.33$ & $0.28 \pm 22.74$ \\
\hline III & $131.60 \pm 9.55$ & $128.48 \pm 21.91$ & $-3.12 \pm 18.37$ \\
\hline IV & $120.55 \pm 13.17$ & $143.23 \pm 24.44$ & $22.68 \pm 20.08^{*}$ \\
\hline $\mathbf{V}$ & $137.22 \pm 17.21$ & $127.63 \pm 27.06$ & $-9.58 \pm 37.34$ \\
\hline VI & $128.57 \pm 18.80$ & $160.12 \pm 32.05$ & $31.55 \pm 14.73^{*}$ \\
\hline VII & $170.75 \pm 25.44$ & $173.65 \pm 57.03$ & $2.90 \pm 49.21$ \\
\hline VIII & $153.10 \pm 30.34$ & $171.10 \pm 15.57$ & $18.00 \pm 20.98$ \\
\hline P value & $0.001^{\mathrm{a}}$ & $0.018^{a}$ & $0.187^{a}$ \\
\hline
\end{tabular}

The role of probiotics and prebiotics in diabetes is related to the microbiota modification in the gut. The probiotic-prebiotic combination (synbiotic) could change the predominant bacteria and increase the SCFA production in the intestine. The production of SCFA by these bacteria has the potential to act as an effector of intestinal epithelial proliferation regulation [12]. A study by Shafi $e t$ al. [13] showed that the administration of fermented milk with Lactobacillus acidophilus that enriched with prebiotics could significantly reduce blood glucose levels in a diabetic rabbit model. Research by Moroti et al. [14] examined the administration of synbiotic shake containing Lactobacillus acidophilus, Bifidobacterium bifidum, and FOS also showed a significant reduction in fasting blood glucose levels in elderly subjects with type 2 diabetes mellitus.

The insignificant results in this study could be caused by a lack of intervention duration in administering the synbiotic shake intervention. According to Shah and Swami [15], probiotics may not affect glycemic parameter when the study duration is too short. Probiotics could provide beneficial effects on the blood glucose level when administered for moderate to the long term duration of around 8 weeks [15]. The results of the meta-analysis conducted by Nikbakht et al. [1] showed that probiotic supplementation appeared to be more successful when given for more than 8 weeks. The increase in blood glucose levels in the intervention group could be caused by the level of blood glucose before the intervention was not too high. According to Nikbakht et al. [1], the effect of 
probiotics and synbiotics administration could be influenced by initial blood glucose levels. LeBlanc et al. [12] also found that the effect of SCFA on body glucose metabolism will be more clearly seen if the balance in the intestine is disturbed.

In this study, the blood glucose levels of rats in the group that received synbiotic shakes with inulin had improved when compared to the synbiotic shake with FOS. That could be due to the inulin characteristics that it has a longer polymerization degree compared to FOS so that inulin has a more persistent effect in the colon. The chain length of fructans is an important factor that determines its physiological effects [16]. Carbohydrates structures with different chain lengths determine quite different physiological responses [17]. A study by Stewart et al. [16] found that FOS had a higher rate of SCFA production than inulin during a time interval of 0-4 hours. However, at 12-24 hours, inulin has a faster SCFA production rate than FOS. Short-chain fructans ferment faster so that fermentation occurred in the proximal colon, while long-chain fructans ferment stably [16].

\subsection{Effect of Synbiotic Shake Administration on Lipid Profile}

Dyslipidemia is the main factor in cardiovascular disease in the form of lipid metabolism disorders characterized by increased VLDL, LDL, triglycerides levels, and decreased HDL levels [18]. Lipid metabolism disorder caused by the insulin resistance conditions along with hyperglycemia results in excessive lipoprotein production, the cause of hypertriglyceridemia conditions accompanied by modification of other lipid particles, such as HDL [19]. Triglycerides, LDL, and HDL are important parameters that need to be concerned considering their contribution as the main cause of death complications in individuals with increased blood glucose levels [20].

This study reported that the intervention of synbiotic shake with a variety of prebiotics Lactobacillus acidophilus La5 and Bifidobacterium lactis Bb12 could affect the lipid profile of hyperglycemic rats. After 4 weeks, the results showed an insignificant increase in LDL levels in all groups ( $p>0.05$ ) except in group I, group IV, and group V with an increase in each group was $4.03 \pm$ $2.32 \mathrm{mg} / \mathrm{dL}, 4.05 \pm 3.32 \mathrm{mg} / \mathrm{dL}$, and $8.31 \pm 2.78 \mathrm{mg} / \mathrm{dL}$ (Table 5). It was found that synbiotic shake administration could maintain LDL levels in the intervention group other than in group IV and in group V. The results of the statistical analysis also showed that synbiotic shake administration significantly increased HDL levels $(p<0.05)$ in group $V$ and group VI (Table 5). Group V experienced an increase in HDL levels from $33.28 \pm 3.81 \mathrm{mg} / \mathrm{dL}$ to $46.98 \pm 6.88$ $\mathrm{mg} / \mathrm{dL}$ and group VI experienced an increase in HDL levels from $39.15 \pm 7.94 \mathrm{mg} / \mathrm{dL}$ to $44.07 \pm 9.37$ $\mathrm{mg} / \mathrm{dL}$. The largest increase in HDL levels was in group $\mathrm{V}$ or in the treatment group synbiotic shake with probiotic La-5 and prebiotic FOS, which was $13.70 \pm 6.27 \mathrm{mg} / \mathrm{dL}$. 
Table 5. LDL and HDL Cholesterol Level During the Study

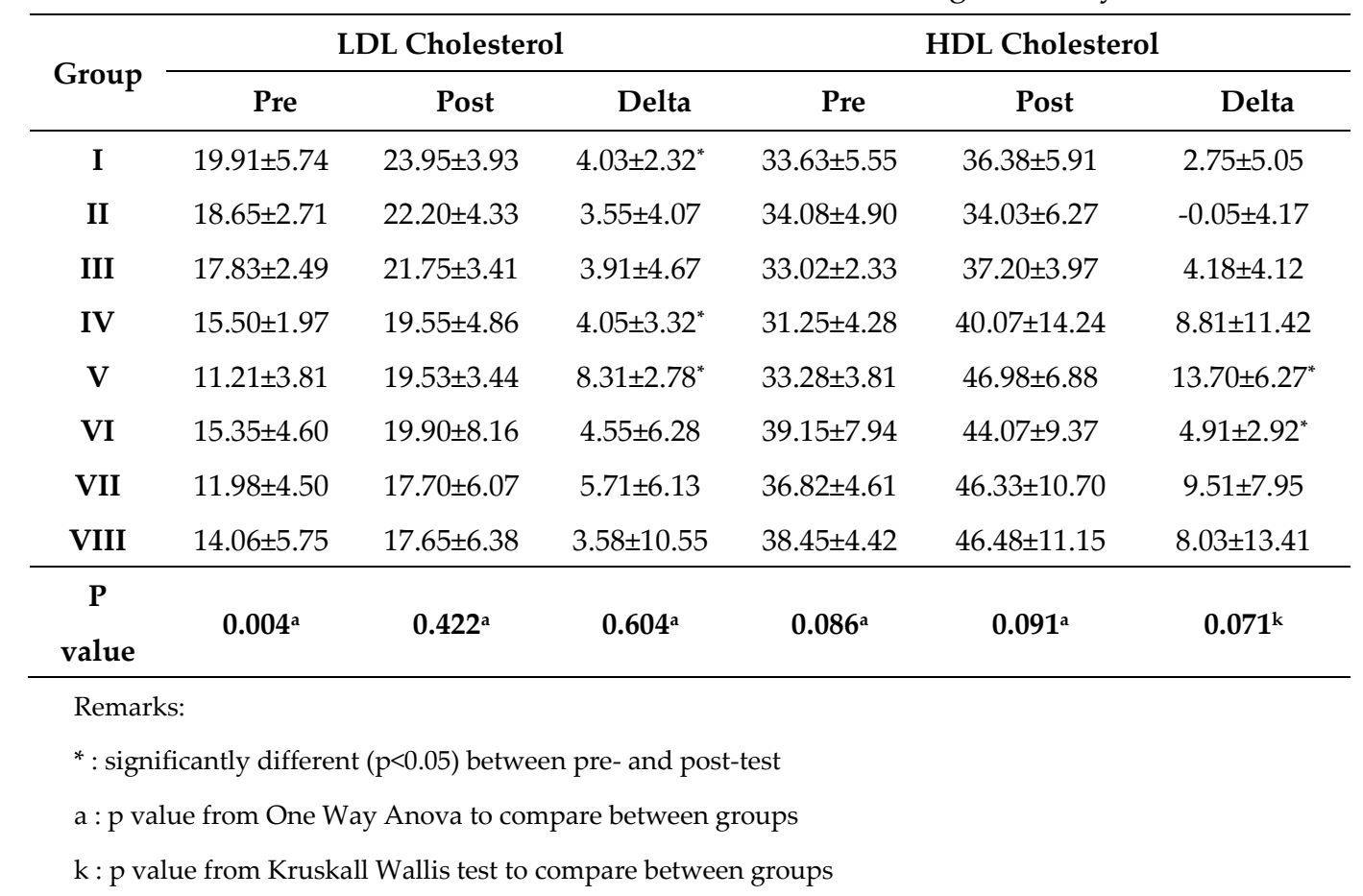

Synbiotic shake administration was able to maintain triglyceride levels, but not in group VI that increased significantly $(\mathrm{p}<0.05)$ from $145.88 \pm 79.97 \mathrm{mg} / \mathrm{dL}$ became $192.73 \pm 76.01 \mathrm{mg} / \mathrm{dL}$. When compared with the hyperglycemic rats' group that were only given distilled water, synbiotic shakes administration did not have a significant difference $(p>0.05)$ on triglyceride levels (Table 6).

Table 6. Triglycerides Level During the Study

\begin{tabular}{cccc}
\hline \multirow{2}{*}{ Group } & \multicolumn{3}{c}{ Triglycerides } \\
\cline { 2 - 4 } & Pre & Post & Delta \\
\hline I & $73.78 \pm 30.68$ & $56.22 \pm 12.67$ & $-17.57 \pm 30.22$ \\
II & $70.73 \pm 26.46$ & $109.90 \pm 58.37$ & $39.17 \pm 35.52^{*}$ \\
III & $76.75 \pm 10.14$ & $121.12 \pm 54.23$ & $44.37 \pm 48.78$ \\
IV & $77.83 \pm 26.04$ & $62.15 \pm 39.66$ & $-15.68 \pm 46.27$ \\
V & $122.60 \pm 29.49$ & $124.77 \pm 48.22$ & $2.17 \pm 41.39$ \\
VI & $145.88 \pm 79.97$ & $192.73 \pm 76.01$ & $46.85 \pm 11.45^{*}$ \\
VII & $118.02 \pm 29.13$ & $82.40 \pm 37.40$ & $-35.60 \pm 41.38$ \\
VIII & $119.75 \pm 37.00$ & $141.12 \pm 36.61$ & $21.37 \pm 54.04$ \\
\hline P value & $\mathbf{0 . 0 0 9 k}$ & $\mathbf{0 . 0 0 2}$ & \\
\hline
\end{tabular}

Remarks:

* : significantly different $(\mathrm{p}<0.05)$ between pre- and post-test

$\mathrm{a}: \mathrm{p}$ value from One Way Anova to compare between groups

$\mathrm{k}: \mathrm{p}$ value from Kruskall Wallis test to compare between groups 
The earlier research had shown that synbiotic shakes could improve lipid profiles. A study conducted by Moroti et al. [14] which aimed to evaluate the effect of consuming a synbiotic shake contained Lactobacillus acidophilus, Bifidobacterium bifidum and FOS in the elderly showed that consumption of $200 \mathrm{~mL}$ synbiotic shake for 4 weeks showed a significant increase in HDL levels from $43.33 \mathrm{mg} / \mathrm{dL}$ to $58.56 \mathrm{mg} / \mathrm{dL}$, the decrease in total cholesterol, and the insignificant changes in triglyceride. Another study by Yang et al. [21] showed that synbiotics administration contained Bifidobacterium, Lactobacillus acidophilus, and inulin to hyperlipidemic rats for 8 weeks was able to reduce triglyceride, cholesterol, and LDL levels significantly. Research conducted on experimental pigs by administered synbiotics contained Lactobacillus acidophilus, FOS, inulin, and mannitol for 8 weeks showed a significant reduction in serum triglyceride, cholesterol, and LDL as well as increased HDL levels in hypercholesterolemic pigs [22].

The mechanism that explains the improvement of lipid profiles by synbiotics administration varies exceedingly, including through intestinal microbiota composition improvement by probiotics thus that it can reduce the LPS production which could trigger inflammation, cholesterol assimilation in the probiotic bacteria cell walls, bile acids deconjugation by BSH, and SCFA production by prebiotics [23,24]. Cholesterol assimilation and bile acid deconjugation inhibit the absorption of cholesterol in the intestine resulting in circulating cholesterol levels decrease [24]. Inflammation improvement by decreasing LPS production could improve insulin resistance thus that it can maintain blood glucose stability and improve lipid profiles in the form of triglycerides, LDL, and HDL [25].

The difference in the results of this study with previous studies might be due to conditions differences of the study population and the incompatibility of probiotic strains and their dosages as well as the culture used differences [26]. In addition, differences in the results of using probiotics in the study could also be due to the quantity, species, strains of probiotics, probiotic doses, probiotic carriers, time of intervention, sample size, clinical characteristics of participants, or different study designs differences [4]. The results of the meta-analysis conducted by Nikbakht et al. [1] showed that probiotic supplementation appeared to be more successful when administered for more than 8 weeks. Another study compared feeding rats contained FOS showed the results of the group of rats fed with a dry artichoke diet contained FOS when compared to the control group showed a significant reduction in triglyceride levels at week 6 and 8 of the intervention and showed no significant changes in triglyceride levels at 2 nd and 4 th week of interventions [27].

\section{CONCLUSION}

The administration of synbiotic shakes with a variety of prebiotics Lactobacillus acidophilus La5 and Bifidobacterium lactis Bb12 for 4 weeks were able to maintain fasting blood glucose levels and lipid profiles in hyperglycemic rats. When compared with the hyperglycemic rats' group that was only administered with distilled water, synbiotic shakes administration did not have a significant difference ( $p>0.05$ ) on changes in fasting blood glucose, LDL, HDL, and triglyceride levels. 
Funding: This research was funded by Faculty of Medicine, Public Health, and Nursing, Universitas Gadjah Mada, grant number 1479/UN1/FK-KMK/PP/PT/2019.

Acknowledgments: The authors thank to Chr. Hansen Malaysia Sdn. Bhd. Jakarta representative office and PT. Brenntag for supporting Lactobacillus acidophilus La- $5^{\circledR}$ and Bifidobacterium animalis subsp. lactis $\left(\mathrm{BB}-12^{\circledR}\right)$.

Conflicts of interest: The authors declare no conflict of interest.

\section{References}

1. Nikbakht, E., Khalesi, S., Singh, I., Williams, L. T., West, N. P., \& Colson, N. Effect of Probiotics and Synbiotics on Blood Glucose: a Systematic Review and Meta-Analysis of Controlled Trials. Eur J Nutr 2018, 57(1), 95-106.

2. American Diabetes Association. Diagnosis and Classification of Diabetes Mellitus. Diabetes Care 2014, 37(1), 81-90.

3. Fatimah, R. N. Diabetes Melitus Tipe 2. Jurnal Majority 2015, 4(5), 93-101.

4. Rezaei, M., Sanagoo, A., Jouybari, L., Behnampoo, N., \& Kavosi, A. The effect of probiotic yogurt on blood glucose and cardiovascular biomarkers in patients with type II diabetes: A randomized controlled trial. Evidence Based Care Journal 2017, 6(4), 26-35. https://doi.org/10.22038/ebcj.2016.7984

5. PERKENI. Pengelolaan dan Pencegahan Diabetes Melitus Tipe 2 di Indonesia 2015. Jakarta 2015. PB. Perkeni (Pengurus Besar Endokrinologi Indonesia)

6. Martirosyan, D. M., \& Singh, J. A New Definition for Functional Food by FFC: Creating Functional Food Products Using New Definition. In Introduction to functional food science (3rd edition, pp 10-24). San Diego. 2015. Functional Food Center Inc.

7. Laitinen, K., Poussa, T., \& Isolauri, E. (2009). Probiotics and Dietary Counselling Contribute to Glucose Regulation During and After Pregnancy: a Randomised Controlled Trial. Br J Nutr 2009, 101, 1679-1687.

8. Joyce, S.A., MacSharry, J., Casey, P.G., Kinsella, M., Murphy, E.F, Shanahan, F., Hill, C., \& Gahan, C.G.M. Regulation of Host Weight Gain and Lipid Metabolism by Bacterial Bile Acid Modification in the Gut. PNAS 2014, 111(20), 7421-7426.

9. Reeves, P. G. Symposium: Animal Diets for Nutritional and Toxicological Research Components of the AIN93 Diets as Improvements in the AIN-76A Diet. American Society for Nutritional Sciences 1997, 838-841.

10. Ortiz-Andrade, R. R., Sánchez-Salgado, J. C., Navarrete-Vázquez, G., Webster, S. P., Binnie, M., GarcíaJiménez, S., León-Rivera, I., Cigarroa-Vázquez, P., Villalobos-Molina, R. \& Estrada-Soto, S. Antidiabetic and toxicological evaluations of naringenin in normoglycaemic and NIDDM rat models and its implications on extra-pancreatic glucose regulation. Diabetes Obes Metab 2008, 10, 1097-1104. doi: 10.1111/j.14631326.2008.00869.x

11. Ojiako, O. A., Chikezie, P. C., \& Ogbuji, A. C. Blood Glucose Level and Lipid Profile of Alloxan-induced Hyperglycemic Rats Treated with Single and Combinatorial Herbal Formulations. J Tradit Complement Med 2016, 6, 184-192.

12. LeBlanc, J. G., Chain, F., Martín, R., Bermúdez-Humarán, L. G., Courau, S., \& Langella, P. Beneficial Fffects on Host Energy Metabolism of Short-Chain Fatty Acids and Vitamins Produced by Commensal and Probiotic Bacteria. Microb Cell Fact 2017, 16(1):79, 1-10.

13. Shafi, A., Naeem Raja, H., Farooq, U., Akram, K., Hayat, Z., Naz, A., \& Nadeem, H. R. Antimicrobial and Antidiabetic Potential of Synbiotic Fermented Milk: A functional dairy product. Int J Dairy Technol 2019, 72(1), 15-22.

14. Moroti, C., Magri, L. F., Costa, M. d., Cavallin, D. C., \& Sivieri, K. Effect of The Consumption of a New Symbiotic Shake on Glycemia and Cholesterol Levels in Elderly People with Type 2 Diabetes Mellitus. Lipids Health Dis 2012, 11(29), 1-8.

15. Shah, N. J., \& Swami, O. C. Role of Probiotics in Diabetes: a Review of Their Rationale and Efficacy. EMJ Diabetes 2017, 5(1), 104-110.

16. Stewart, M. L., Timm, D. A., \& Slavin, J. L. Fructooligosaccharides Exhibit More Rapid Fermentation than Long-Chain Inulin in an in vitro Fermentation System. Nutr Res 2008, 28(5), 329-334.

17. Rossi, M., Corradini, C., Amaretti, A., Nicolini, M., Pompei, A., Zanoni, S., \& Matteuzzi, D. Fermentation of Fructooligosaccharides and Inulin by Bifidobateria: a Comparative Study of Pure and Fecal Cultures. Appl Environ Microbiol 2005, 71(10), 6150-6158.

18. Parhofer, K. G. Interaction Between Glucose and Lipid Metabolism: more than diabetic dyslipidemia. Diabetes Metab J 2015, 39(5), 353-362. 
19. Quispe, R., Martin, S. S., \& Jones, S. R. Triglycerides to High-Density Lipoprotein-Cholesterol Ratio, Glycemic Control and Cardiovascular Risk in Obese Patients with Type 2 Diabetes. Curr Opin Endocrinol Diabetes Obes 2016, 23(2), 150-156.

20. Ejtahed, H. S., Mohtadi-Nia, J., Homayouni-Rad, A., Niafar, M., Asghari-Jafarabadi, M., Mofid, V., \& Akbarian-Moghari, A. Effect of Probiotic Yogurt Containing Lactobacillus acidophilus and Bifidobacterium lactis on Lipid Profile in Individuals with Type 2 Diabetes Mellitus. J Dairy Sci 2011, 94(7), 3288-3294.

21. Yang, R., Wang, C., Ye, H., Gao, F., Cheng, J., Zhang, T., \& Guo, M.. Effects of Feeding Hyperlipidemia Rats with Symbiotic Oat-Based Frozen Yogurt on Serum Triglycerides and Cholestero. Food Sci Nutr 2019, 7(3), 1096-1103.

22. Liong, M.-T., Dunshea, F. R., \& Shah, N. P. Effects of a Synbiotic Containing Lactobacillus acidophilus ATCC 4962 on Plasma Lipid Profiles and Morphology of Erythrocytes in Hypercholesterolaemic Pigs on High- and Low-Fat Diets. Br J Nutrn 2007, 98, 736-744.

23. Eslamparast, T., Poustchi, H., Zamani, F., Sharafkhah, M., Malekzadeh, R., \& Hekmatdoost, A. Synbiotic Supplementation in Nonalcoholic Fatty Liver Disease: A Randomized, Double-Blind, Placebo-Controlled Pilot Study. Am J Clin Nutr 2014, 99(3), 535-542.

24. Ooi, L.-G., \& Liong, M.-T. Cholesterol-Lowering Effects of Probiotics and Prebiotics: A Review of in Vivo dan in Vitro Findings. Int J Mol Sci 2010, 11, 2499-2522.

25. Rajkumar, H., Kumar, M., Das, N., Kumar, S. N., Challa, H. R., \& Nagpal, R. Effect of Probiotic Lactobacillus salivarius UBL S22 and Prebiotic Fructo-Oligosaccharide on Serum Lipids, Inflammatory Markers, Insulin Sensitivity, and Gut Bacteria in Healthy Young Volunteers: A Randomized Controlled Single-Blind Pilot Study. J Cardiovasc Pharmacol Ther 2015, 20(3), 289-298.

26. Asemi, Z., Zare, Z., Shakeri, H., Sabihi, S. S., \& Esmaillzadeh, A. Effect of Multispecies Probiotic Supplements on Metabolic Profiles, hs-CRP, and Oxidative Stress in Patients with Type 2 Diabetes. Ann Nutr Metab 2013, 63(1-2), 1-9.

27. Moharib, S. A., Shehata, M. M., Salama, A. F., \& Hegazi, M. A. Effect of Fructooligosaccharides in Cynara Scolymus and Allium Cepa on Carbohydrate and Lipid Metabolism in Rat. EJPAU 2014, 17(2).

(C) 2020 by the authors. Submitted for possible open access publication under the terms and conditions of the Creative Commons Attribution (CC BY) license (http://creativecommons.org/licenses/by/4.0/). 